\title{
Optical Coherence Tomography: Age estimation of Calliphora vicina pupae in vivo?
}

\author{
Katherine Brown ${ }^{1} \&$ Michelle Harvey ${ }^{2}$ \\ ${ }^{1}$ School of Biological Sciences, University of Portsmouth, King Henry Building, King Henry I Street, \\ Portsmouth, PO1 2DY, England. \\ ${ }^{2}$ Present address: School of Life and Environmental Sciences, Deakin University, Waurn Ponds, \\ Victoria, Australia 3217. \\ Email: katherine.brown@port.ac.uk; michelle.harvey@deakin.edu.au \\ Phone: +44 (0) 2392845012 \\ * = corresponding author
}

\section{Abstract}

Necrophagous blowfly pupae are valuable contributors to the estimation of post-mortem interval, should an accurate age estimate be obtained. At present, this is reliant on a combination of rearing and destructive methods conducted on preserved samples, including morphological observation and gene expression analyses. This study demonstrates the use of optical coherence tomography (OCT) as a tool for in vivo morphological observation and pupal age estimation. Using a Michelson OCT microscope, alive and preserved four and ten-day old Calliphora vicina pupae were scanned in different orientations. Two and three-dimensional images were created. Morphological characteristics such as the brain, mouthparts and legs were identifiable in both living and preserved samples, with distinct differences noted between the two ages. Absorption of light by the puparium results in a vertical resolution of $1-2 \mathrm{~mm}$, preventing observation of deeper tissues. The use of contrast agents or a longer wavelength laser would improve the images obtainable. At present, the data suggests OCT provides a primary view of external and internal morphology, which can be used to distinguish younger and older pupae for further analysis of age and PMI estimation.

\section{Key words}

Calliphora vicina, forensic entomology, pupae, age estimation, optical coherence tomography, microscopy

\section{Highlights}

- We examine OCT microscopy as a tool for in vivo pupal age estimation

- $\quad$ Alive and preserved Calliphora vicina pupae were observed in 2D and 3D

- Brain, mouthparts and legs were identifiable in four- and ten-day old pupae

- The current maximum of 1-2 $\mathrm{mm}$ depth penetration limits observations

- We suggest OCT provides a complimentary method of pupal age estimation 


\section{Introduction}

Pupae, a sedentary and long-lasting stage of the blowfly lifecycle, are often reported at crime scenes in association with a cadaver [1-3]. They are valuable contributors to post-mortem interval (PMI) estimation, provided an accurate age estimate can be obtained. This is generally conducted by rearing pupae under controlled conditions [4], which takes up to two weeks at room temperature and the accuracy of estimates decrease with later lifecycle stages [5]. Consequently and additionally, rapid age estimation from pupae can also be conducted from preserved samples, giving a more reliable estimate of PMI.

Age can be estimated from correctly preserved pupae using analysis of external morphology, histology and developmental gene expression [6-11], with an accuracy of $+/-12$ hours (at $22^{\circ} \mathrm{C}$ ) [10]. The dissection and/or homogenisation required for these methods can destroy the pupa. Whilst this causes minimal problems when large numbers of pupae are collected from the scene, when only a small sample is available, the preferred multidisciplinary approach to age estimation may not be possible. For example, it is likely that initial external morphological examination of a single pupa may inhibit subsequent gene expression analysis on the same organism, therefore it is advantageous if age estimates can be made without damaging the pupa.

Negating the need for histological sectioning and resulting tissue loss [6], methods such as X-ray imaging, micro computed tomography (micro CT), synchrotron X-ray microtomography (SR- $\mu \mathrm{CT}$ ) and magnetic resonance microscopy (MRM) enable production of 2D and 3D images of insects [7,12-15]. Whilst SR- $\mu$ CT resolution is $\sim 1 \mu \mathrm{m}$ [16], the equipment size and costs are prohibitively high for routine forensic use. In contrast, the resolution of micro CT and MRM is low [7], and this can only at present be improved using freeze-drying [17], staining with phosphotungstic acid (PTA) [13] or iodine [7] or injection with contrast agents [18]. Undesirably, these modifications would interfere with other age estimation methods and may kill and detrimentally alter the pupae.

The optimal non-destructive technique for age estimation is the analysis of living pupae, as this permits multiple further analyses including rearing. Sarcophaga peregrina pupal head eversion has been observed in vivo using MRM [19] however movement generally causes blurring [20]. The highest quality images are those of static organs such as the brain [21-24] but as mentioned previously resolution is still low and this technique is still considered complementary to histology on larger insects [20].

Optical coherence tomography (OCT) is a more recently developed microscopy technique than MRM and micro CT. The OCT microscope is considerably smaller (bench-top sized) and cheaper than other high-resolution microscopy equipment, and it is relatively simple to operate. It displays a resolution of $<5 \mu \mathrm{m}$, superior to those achievable using MRI and some micro CT equipment. Slice thicknesses of 2- 
$20 \mu \mathrm{m}$ are achievable, with imaging depths of up to $3 \mathrm{~mm}$ depending on tissue type [25,26], making the method comparable to histological preparations. This study assesses the suitability of OCT for in vivo morphological examination of Calliphora vicina pupae, with the aim of reducing reliance on destructive observation methods for age and PMI estimation.

\section{Materials and Methods}

Colony establishment

Adult Calliphora vicina were collected in Portsmouth, UK (50 47' 51.08' N, $1^{\circ} 5^{\prime} 46.87^{\prime \prime}$ W) using liverbaited flytraps made from $2 \mathrm{~L}$ plastic bottles. Colonies, housed in BugDorms (http://bugdorm.megaview.com.tw), were established from these individuals and maintained at $22^{\circ} \mathrm{C}, 40-60 \%$ relative humidity and under a 16L:8D photoperiod. Flies were fed water and sugar, and provided liver for oviposition.

\section{Collection of pupae}

Under the same environmental conditions for adults, eggs were collected on ox liver placed in a small plastic container $(17 \mathrm{~cm} \times 11 \mathrm{~cm} \times 5 \mathrm{~cm})$ in the BugDorm. The container was then removed after a few hundred eggs were laid and placed in a larger plastic container $(28 \mathrm{~cm} \times 28 \mathrm{~cm} \times 11 \mathrm{~cm})$, on a bed of sand for pupation. Upon hatching, the larvae were reared on liver ad libitum. The aim of this study was to assess the technique for observation of gross morphological change, therefore precise pupal age was not required and so in-colony temperatures were not recorded. Pupae remained undisturbed in the larger container where they were reared to $30-40 \%$ and $>90 \%$ developed and five were sampled (Table 1 ) at four days (4d) and ten days (10d) post-puparium formation respectively. They were collected alive and also fixed by piercing and hot-water-killing [8]. The emergence of live pupae, after scanning, was briefly monitored.

\section{OCT microscopy}

Puparia remained intact for living pupae and were removed from fixed pupae prior to visualisation. The EX 1301 swept source OCT microscope (Michelson Diagnostics) used in this study employs multiple, simultaneously stacked lasers to scan the sample, up to a speed of 30 frames per second. Pupae were placed on the motorised stage in different orientations and the microscope was set to scan at 8-12 $\mu \mathrm{m}$ (Table 1). The two-dimensional cross-section images obtained were produced from the attenuated and backscattered near-infrared light.

Scans were saved as stacks of TIFF files, and viewed in Voxx (http://www.nephrology.iupui.edu/ imaging/voxx), Image J (http://rsbweb.nih.gov/ij) and Vaa3D (http://www.vaa3d.org) as two- 
dimensional stacks and in rendered 3D models. 3D models were virtually sectioned on all three axes $(x, y$ and $z)$ to reveal internal anatomy.

\section{Results}

The purpose of this study was to explore OCT microscopy as a potential tool for age estimation of pupae in vivo, for PMI estimation. For comparison and assessment of OCT capabilities, pupae were also examined in vitro, after preservation.

Dorsal longitudinal sections of $4 \mathrm{~d}$ live pupae allowed visualisation of some internal structures through the puparium such as the abdomen, wings, posterior trachea as well as the developing brain (Fig. 1a, b). The transverse section shows everted respiratory horns (Fig. 1c). Saggital sections also show the brain to a depth of $\sim 1 \mathrm{~mm}$ (Fig. 1d). Longitudinal ventral and transverse sections of live 10d pupae similarly revealed external features such as the labellum, labrum, brain and leg musculature (Fig. 1f, g, h). 3D rendering of live pupae (Fig. 1e) resulted in a view of the external puparium surface. The pupae emerged successfully within the same time frame as the cohort from which they were sampled.

Whole 3D rendered images of preserved 4d pupae showed antennae, wing and leg detail on the ventral surface (Fig. 2a). Leg musculature and tarsi were viewed both in ventral transverse (Fig. 2b) and longitudinal (Fig. 2c, d) sections respectively. These longitudinal cut away sections also showed outlines of wing tissue, eyes and antennae, and mouthparts in considerable detail (Fig. 2c, d). 3D surface rendered images and cut away sections of $10 \mathrm{~d}$ pupae showed compound eyes, orbital bristles and optic neurons (Fig. 2e, g). Sagittal and dorsal stacks showed eyes, antennae, abdominal macrochaetae, legs and wing folding detail (Fig 2f, h).

\section{Discussion and Conclusion}

OCT is commonly used for in vivo examination of retinas, blood vessels and skin carcinomas (summarised in [25]; see also [27]) but also in developmental biology to examine mammals (reviewed by [28]) and Xenopus spp. [29-31]. This pilot study using OCT microscopy for imaging of blowfly pupae aimed to test whether enough morphology information could be obtained without dissection or histology for age estimation. Non-destructive in vivo methods are clearly advantageous and would permit further age estimation analyses, such as gene expression $[9,11]$, to be performed.

The data shows that whilst many important morphological developments, e.g. mouthparts, brain and bristles [32] were visible in vivo using OCT, many of the features lacked in detail due to the main limitation of the OCT system used here; the lack of vertical resolution. The tissues, especially the puparium, absorb the light strongly, limiting penetration to $1-2 \mathrm{~mm}$ and resolution is lost. Preservation and puparium removal allowed further details in wing folding and bristle formation to be observed; this permits more reliable differentiation between the two ages of pupae, demonstrates the 
significance of the back scattering effect and finally highlights the technique's potential could back scattering be reduced. This problem was also evidenced in Drosophila melanogaster larvae [33,34]; their transparent organs lie beneath an opaque cuticle which causes much of the light back scattering before penetration of the sample can occur. In contrast, daily development of lepidopteran wings [35], which lie just beneath the surface of the puparium, has been observed.

There have been no previously reported cases of damage or death of any tissue analysed by OCT; similarly and importantly in this study, pupae were observed to emerge as normal. Clearly, extensive quantitative analysis of any possible effects on pupal age and morphology effects caused by OCT scanning must be conducted prior to acceptance as a suitable in vivo technique for PMI estimation.

The tissue contrast required for the operation of OCT was enhanced by the sclerotisation of $10 \mathrm{~d}$ pupae. This increased the light back scattering and improved surface and internal resolution. It is considered that OCT would therefore be most suited to age estimation of older pupae. Recent advances to the equipment are that of enhanced tissue differentiation based on elasticity/stiffness (Michelson Diagnostics, pers. comm.) and this could facilitate identification of external features and internal tissue types, such as bristles and trachea respectively. Unfortunately, the use of OCT for age estimation of preserved pupae offers no advantage over standard external morphological examination, which provides more accurate age estimates. Age estimation of live pupae using OCT would, however, be advantageous to PMI estimation; estimates may be accurate to within a few days (based on gross morphological changes), providing an initial assessment prior to rearing of the pupa to eclosion [4], or performing targeted age estimation using other methods such as gene expression [9].

Current costs of an OCT microscope are within the realms of a research-standard stereomicroscope one-quarter that of a micro CT system - making this a more likely and realistic addition to a forensic laboratory. Prior to investment however, for OCT to be adopted for morphological analysis, the vertical resolution or penetration depth must be improved. This could be achieved by using a laser with a longer wavelength than $1130 \mathrm{~nm}$, such that the tissue absorbs less light. A more recently developed microscope (OCS1300SS; www.thorlabs.de) utilises a 1300nm laser, which provides a slightly better penetration depth of $3 \mathrm{~mm}$, however depths of $4-5 \mathrm{~mm}$ would be desirable for pupae.

The injection of contrast agents such as microspheres into living organisms has been shown to improve image quality, by increasing the light-scattering properties of the tissues [36,37]. This method would require the pupa to remain alive for a currently unknown period of time sufficient for this to occur, reducing the accuracy of age and PMI estimation. Microspheres may also then inhibit additional age estimation methods, such as gene expression analysis or rearing to eclosion and therefore negate the benefit of in vivo observation. 
In conclusion, this work has demonstrated that rudimentary morphological analysis of pupae in vivo is possible using an OCT microscope. Differences in $4 \mathrm{~d}$ and $10 \mathrm{~d}$ pupal morphology was distinct enough such that ages were identifiable, thus this technique shows potential as a tool for approximate age and PMI estimation. Although the results are promising, for OCT microscopy to be considered a more useful tool for age estimation using external morphology and/or histological examination, technological improvements must be made.

\section{References}

[1] Greenberg B. Forensic entomology: case studies. Bull ESA 1985.

[2] Benecke M. Six forensic entomology cases: description and commentary. J Forensic Sci 1998;43:797-805.

[3] Amendt J, Krettek R, Niess C, Zehner R, Bratzke H. Forensic entomology in Germany. Forensic Sci Int 2000;113:309-14.

[4] Amendt J, Campobasso CP, Gaudry E, Reiter C, LeBlanc HN, JR Hall M. Best practice in forensic entomology-standards and guidelines. Int J Legal Med 2007;121:90-104.

[5] Tarone AM, Foran DR. Gene expression during blow fly development: improving the precision of age estimates in forensic entomology. J Forensic Sci 2011;56:S112-S122.

[6] Davies K, Harvey M. Internal morphological analysis for age estimation of blow fly pupae (Diptera: Calliphoridae) in post-mortem interval estimation. J Forensic Sci 2013;58:79-84.

[7] Richards CS, Simonsen TJ, Abel RL, Hall MJR, Schwyn DA, Wicklein M. Virtual forensic entomology: Improving estimates of minimum post-mortem interval with 3D micro-computed tomography. Forensic Sci Int 2012;220:251-64.

[8] Brown K, Thorne A, Harvey M. Preservation of Calliphora vicina (Diptera: Calliphoridae) pupae for use in post-mortem interval estimation. Forensic Sci Int 2012;23:176-83.

[9] Boehme P, Spahn P, Amendt J, Zehner R. Differential gene expression during metamorphosis: a promising approach for age estimation of forensically important Calliphora vicina pupae (Diptera: Calliphoridae). Int J Legal Med 2013;127:243-9.

[10] Brown K. Utility of the Calliphora vicina (Diptera: Calliphoridae) Pupal Stage for Providing Temporal Information for Death Investigations. University of Portsmouth, 2012.

[11] Boehme P, Spahn P, Amendt J, Zehner R. The analysis of temporal gene expression to estimate the age of forensically important blow fly pupae: results from three blind studies. Int J Legal Med 2013.

[12] Greco M, Bell M, Spooner-Hart R, Holford P. X-ray computerised tomography as a new method for monitoring Amegilla holmesi nest structures, nesting behaviour and adult female activity. Entomol Exp Appl 2006;120:71-6.

[13] Metscher BD. MicroCT for comparative morphology: simple staining methods allow highcontrast 3D imaging of diverse non-mineralized animal tissues. BioMed Cent Physiol 2009;9. 
[14] Goodman BA, Gordon SC, Chudek JA, Hunter G, Woodford J. Nuclear-magnetic-resonance microscopy as a non-invasive tool to study the development of lepidopteran pupae. J Insect Physiol 1995;41:419-24.

[15] Westneat MW, Betz O, Blob RW, Fezzaa K, Cooper WJ, Lee W-K. Tracheal respiration in insects visualized with synchrotron $x$-ray imaging. Science 2003;299:558-60.

[16] Zehbe R, Haibel A, Riesemeier H, Gross U, Kirkpatrick CJ, Schubert H, et al. Going beyond histology. Synchrotron micro-computed tomography as a methodology for biological tissue characterization: from tissue morphology to individual cells. J R Soc Interface 2010;7:49-59.

[17] Davies RL, Worrill N, Bowen ID, Harrison TJ, Evans KT. A technique for studying the development, metamorphosis and morphology of insects, using projection X-ray microscopy. J Microsc 1988;149:199-205.

[18] Null B, Liu CW, Hedehus M, Conolly S, Davis RW. High-resolution, in vivo magnetic resonance imaging of Drosophila at 18.8 Tesla. PLoS One 2008;3.

[19] Price WS, Kobayashi A, Ide H, Naori S, Arata Y. Visualising the postembryonic development of Sarcophaga peregrina (flesh fly) by NMR microscopy. Physiol Entomol 1999;24:386-90.

[20] Hart AG, Bowtell RW, Köckenberger W, Wenseleers T, Ratnieks FLW. Magnetic resonance imaging in entomology: a critical review. J Insect Sci 2003;3:9.

[21] Haddad D, Schaupp F, Brandt R, Manz G, Menzel R, Haase A. NRM Imaging of the honeybee brain. J Insect Sci 2004;4:7.

[22] Hallock KJ. Magnetic resonance microscopy of flows and compressions of the circulatory, respiratory, and digestive systems in pupae of the tobacco hornworm, Manduca sexta. J Insect Sci 2005;8:1-7.

[23] Jasanoff A, Sun PZ. In vivo magnetic resonance microscopy of brain structure in unanesthetized flies. J Magn Reson (San Diego, Calif 1997) 2002;158:79-85.

[24] Michaelis T, Watanabe T, Natt O, Boretius S, Frahm J, Utz S, et al. In vivo 3D MRI of insect brain: cerebral development during metamorphosis of Manduca sexta. Neuroimage 2005;24:596-602.

[25] Fujimoto JG. Optical coherence tomography for ultrahigh resolution in vivo imaging. Nat Biotechnol 2003;21:1361-7.

[26] Jenkins M. Longitudinal imaging of heart development with optical coherence tomography. Sel Top Quantum Electron 2011;18:1166-75.

[27] Matheny ES, Hanna NM, Jung W, Chen Z, Wilder-Smith P, Mina-Araghi R, et al. Optical coherence tomography of malignancy in hamster cheek pouches. J Biomed Opt 2004;9:978.

[28] Larina I, Larin K. Optical coherence tomography for live imaging of mammalian development. Curr Opin Genet Dev 2011;21:579-84.

[29] Boppart SA, Bouma BE, Brezinski ME, Tearney GJ, Fujimoto JG. Imaging developing neural morphology using optical coherence tomography. J Neurosci Methods 1996;70:65-72. 
[30] Boppart SA, Tearney GJ, Bouma BE, Southern JF, Brezinski ME, Fujimoto JG. Noninvasive assessment of the developing Xenopus cardiovascular system using optical coherence tomography. Proc Natl Acad Sci U S A 1997;94:4256.

[31] Mariampillai A, Standish BA, Munce NR, Randall C, Liu G, Jiang JY, et al. Doppler optical cardiogram gated 2D color flow imaging at $1000 \mathrm{fps}$ and $4 \mathrm{D}$ in vivo visualization of embryonic heart at $45 \mathrm{fps}$ on a swept source OCT system. Opt Express 2007;15:1627-38.

[32] Brown K, Thorne A, Harvey M. External morphological development of Calliphora vicina (Diptera: Calliphoridae) pupae: a new tool for age and PMI estimation. Int J Legal Med (submitted)

[33] Choma MA, Izatt SD, Wessells RJ, Bodmer R, Izatt JA. In vivo imaging of the adult Drosophila melanogaster heart with real-time optical coherence tomography. Circulation 2006;114:e35.

[34] Bradu A, Ma L, Bloor JW, Podoleanu A. Dual optical coherence tomography/fluorescence microscopy for monitoring of Drosophila melanogaster larval heart. J Biophotonics 2009;2:380-8.

[35] Kambe M, Kinoshita S, Ohmi M, Haruna M. In-vivo Imaging of Developing Wings in Butterfly Pupa by Using Optical Coherence Tomography. J Korean Phys Soc 2008;53:1290-4.

[36] Lee TM, Oldenburg AL, Sitafalwalla S, Marks DL, Luo W, Toublan FJ-J, et al. Engineered microsphere contrast agents for optical coherence tomography. Opt Lett 2003;28:1546-8.

Boppart SA, Suslick KS. Microsphere contrast agents for OCT, 2006, p. 409-27.

Table 1. Description of pupae observed using OCT microscopy. Living and fixed 4 and 10-day old pupae were observed using the OCT microscope with their dorsal, ventral or lateral surfaces upwards. The lateral scanning resolution was either 8 or $12 \mu \mathrm{m}$ as indicated.

\begin{tabular}{|c|c|c|c|c|}
\hline Pupa \# & Age (days) & Condition & Orientation & Resolution \\
\hline 1 & 4 & Alive & Dorsal & $12 \mu \mathrm{m}$ \\
\hline 2 & 4 & Fixed & Ventral & $8 \mu \mathrm{m}$ \\
\hline 3 & 10 & Fixed & Dorsal & $12 \mu \mathrm{m}$ \\
\hline 4 & 10 & Alive & Ventral & $12 \mu \mathrm{m}$ \\
\hline 5 & 10 & Fixed & Lateral & $12 \mu \mathrm{m}$ \\
\hline
\end{tabular}

\section{Figure legends}

Figure 1. OCT images of pupae in vivo 4-day (Table 1: 1) and 10-day old pupae (Table 1: 4) remained alive whilst their dorsal and ventral surfaces were scanned respectively. Images a-d show the 4-day pupa; images e-h show the 10-day pupa. Longitudinal ( $a, b, g$ and $h$ ), transverse (c and f) and sagittal sections (d) were taken. $A$ 3D rendered image of the puparium is also shown (e). $A b=$ abdomen, $B r=$ brain, $\mathrm{La}=$ labellum, Lb = labrum Le = legs, $\mathrm{Pu}=$ puparium, $\mathrm{Re}=$ respiratory horn, $\mathrm{Tr}=$ trachea. 
Figure 2. OCT images of pupae in vitro 4-day (Table 1: 2) and 10-day old pupae (Table 1: 3, 5) were preserved and scanned in multiple orientations after puparium removal. Images a-d show the 4-day pupa; images e-h show the 10-day pupa. Whole and cut-away 3D rendered images (a, e and g) were modelled. Transverse (b), ventral longitudinal (c and d), dorsal longitudinal ( $h$ ) and sagittal sections ( $f$ ) were viewed as single tiff images and taken as slices from the $3 \mathrm{D}$ models. An = antennae, Ey = Compound eye, $\mathrm{La}=$ Labellum, $\mathrm{Lb}=$ labrum, $\mathrm{Le}=$ Legs, $\mathrm{Mc}=$ macrochaetae, $\mathrm{Ob}=$ orbital bristles, $\mathrm{On}=$ optic neurons, $\mathrm{Ta}=$ Tarsi, $\mathrm{Wg}=$ wing.

This paper has been published in Forensic Science International. DOI: 10.1016/j.forsciint.2014.07.001

Brown, K. \& Harvey, M., 2014. Optical Coherence Tomography: Age estimation of Calliphora vicina pupae in vivo? Forensic Science International, 242(September 2014), pp.157-161. Available at: http://www.fsijournal.org/article/S037907381400276X/fulltext [Accessed July 17, 2014]. 
Figure 1

Figure 2
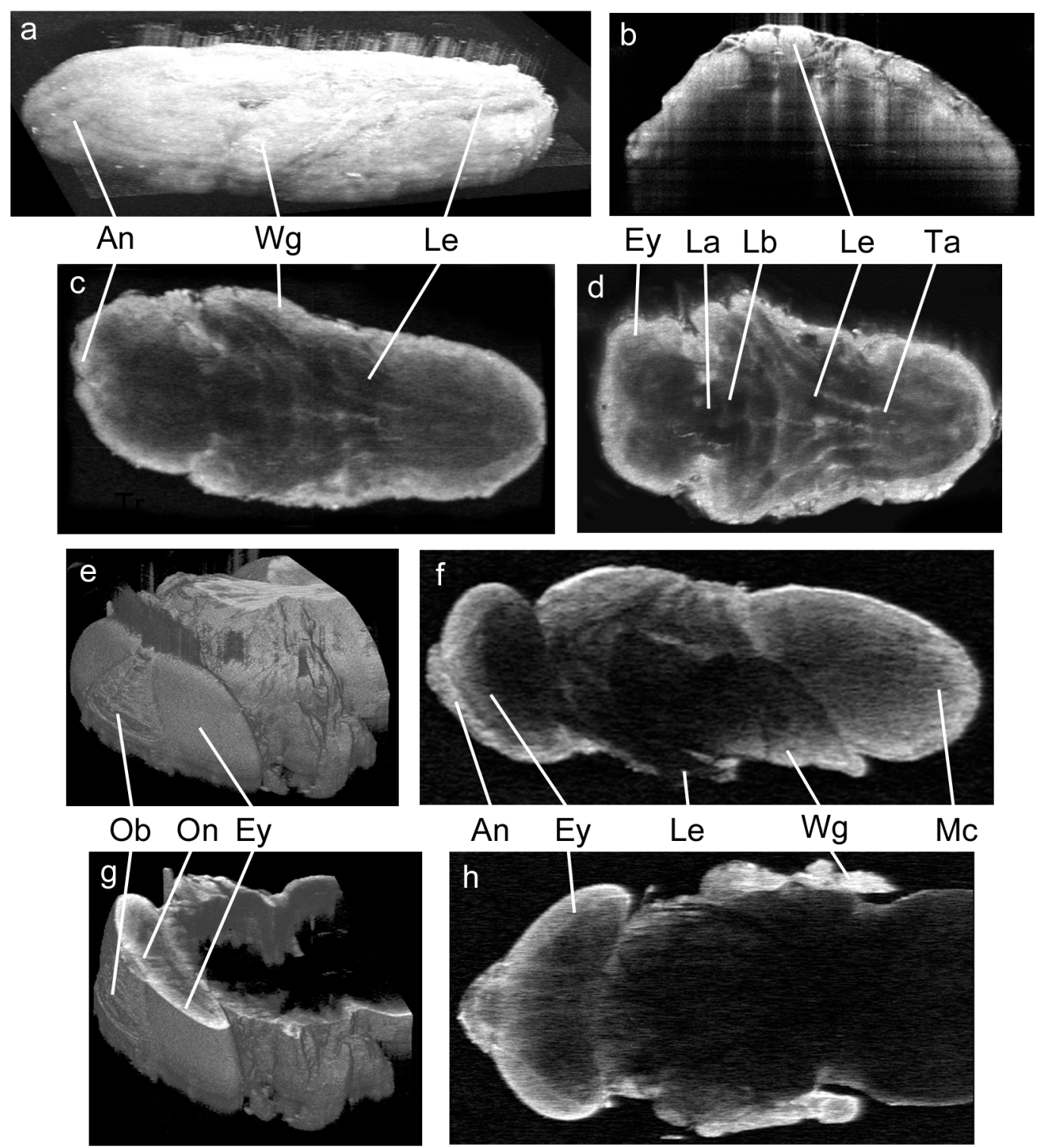